\title{
ARTICLE
}

\section{Exposing the changes in work stress level among Mongolian nurses by salivary Alpha amylase test}

\author{
Otgonbaatar Dondonkhuu ${ }^{1 *}$, Munkhtuya Enkhbayar ${ }^{2}$ \\ Naranbaatar Nyam $^{2}$ and Munkhkhand Jurmeddorj ${ }^{2}$ \\ ${ }^{1}$ Department of Finance and Economics, Mongolian National University of Medical Sciences, \\ Ulaanbaatar, Mongolia. \\ ${ }^{2}$ School of Nursing, Mongolian National University of Medical Sciences, \\ Ulaanbaatar, Mongolia.
}

ARTICLE INFO: Received: 22 Apr, 2020; Accepted: 07 Sep, 2020

Abstract: When stress is part of the work environment, it is difficult to control stress, which can cause recurrent aggression, and which in turn affects an individual's health and ability to act. The relationship between workplace stressors, physical and mental health changes of the nurses have been found. A combination of high workplace demands, over-responsibility, and over-authority have been identified major sources of occupational stress among nursing staff.

A total of 473 nurses from four tertiary referral hospitals of Mongolia were involved in the study. We employed a Work Stress Profile (WSP) questionnaire of Rice to figure out how nurses perceive and accept stress. The Likert scale was used in measuring the questions. Concerning physical stress factor we measured the level of $\alpha$-amylase in the saliva of the nurses using the SALIVA AMYLASE MONITOR 2004, a Japanese device. Fabricated salivary amylase activity monitor consisted of three devices, the salivary transcription device, a testing-strip and an optical analyzer. Firstly, the teststrip was taken and put under the tongue for 30 seconds in the morning.

Occasionally, our study was conducted during the COVID-19 pandemic quarantine period, and we could clearly see that the nurses at National Center for Infectious Diseases are working hard under the urged stressed condition.

Keywords: Stress; workplace stress; nurse; satisfaction; alpha amylase;

\section{INTRODUCTION}

Nursing is a stressful profession, accordingly, nurses are vulnerable to the effects of stress in their daily environment [1]. Workrelated chronic stress leads to fatigue syndrome, lack of ability to work, which are manifested through emotional exhaustion, followed by an emotional numbness or a negative attitude towards oneself and others [2]. It is impossible to wipe out work-related stress and stressors, but only effective coping techniques can help reduce stress-caused outcomes [3].

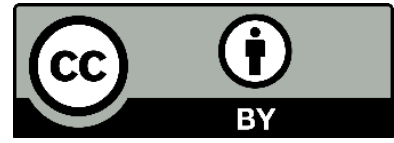

The Author(s). 2020 Open access This article is distributed under the terms of the Creative Commons Attribution 4.0 International License (https://creativecommons.org/licenses/by/4.0/), which permits unrestricted use, distribution, and reproduction in any medium, provided you give appropriate credit to the original author(s) and the source, provide a link to the Creative Commons license, and indicate if changes were made. 
When stress is part of the work environment, it is difficult to control it and it can cause recurrent aggression, which in turn affects an individual's health and ability to act. In fact, sick leave is more common for people who suffer from work stress than other workers. Stressful work environments are prevalent among health professionals, and several studies have been performed regarding the harmful effects of nursing workplace stress $[1,2,3]$. The correlationship between the workplace stressors and nurses' physical and mental health changes were determined in accordance with certain studies [4]. Nursing is considered to be a complex and highly demanding job. A

\section{MATERIALS AND METHODS}

The study involved 473 nurses from the following four tertiary referral hospitals of Mongolia: 1. National Center for Traumatology and Orthopedics (NCTO), 2. National Center for Mental Health (NCMH), 3. National Center for Infectious Diseases (NCID), and 4. National Cancer Center (NCC). The study was conducted over a period of one month from 15 February to 15 March, 2020. We employed a Work Stress Profile (WSP) questionnaire of Rice in 57 questions in 3 domains; the questions aimed at assessing the co-workers relationship (1-26), the working environment (27-48), and the personal attributes (49-57). This questionnaire was designed in a manner so as to figure out how nurses perceive and accept stress. For physical stress factor, we measured the level of $\alpha$-amylase in the saliva of the nurses

\section{RESULTS AND DISCUSSION}

A total of 473 nurses were included in the study, including 121 from NCTO, $89 \mathrm{NCMH}$, 146 from NCID, and 117 from NCC. Meanwhile, 46 administrative workers, 75 combination of the high workplace requirements, over-responsibility, and overauthority have been identified as major sources of occupational stress among nursing staff $[6,7,8]$.

In recent years, there have been a number of stressors, such as emotional instability, anxiety, and worry, due to a variety of factors, including social and economic conditions, dramatic changes in science, technology, information, urbanization, and overcrowding. Nurses who have the closest contact with a client need to study stressful situations in their work.

using the SALIVA AMYLASE MONITOR 2004, a Japanese device. Fabricated salivary amylase activity monitor consisted of three devices, the salivary transcription device, a testing-strip and an optical analyzer. First, he test-strip was taken, which was under the tongue for 30 seconds in the morning.

The Likert scale (1-5) was used in measuring the questions - high level stress 141$167<$, average $-112-140$, and low level stress (>91-111). The indicators were evaluated by a cross-sectional model. The study results tables/graphics and statistical data, were developed and analyzed by Microsoft Excel2018 and Statistical Package for the Social Sciences (SPSS)-25.0. The ANOVA test was held and the statistical difference was $p<0.05$.

doctors, 208 nurse-midwives, 105 cleaners, and 46 organizational workers participated in our study too. The general information of the study participants is shown in Table 1. 


\section{Table 1. General Information of the Study Participants}

\begin{tabular}{|c|c|c|}
\hline \multicolumn{1}{|c|}{ Variables } & Numbers (in percent) & P value \\
\hline Gender & $13(2.7)$ & .525 \\
\hline Male & $460(97.3)$ & \\
\hline Female & & \\
\hline Age group & $34(7.2)$ & .002 \\
\hline $18-24$ & $139(29.4)$ & \\
\hline $25-30$ & $99(20.9)$ & \\
\hline $31-40$ & $169(35.7)$ & \\
\hline $41-50$ & $32(6.8)$ & \\
\hline Above 51 & & \\
\hline
\end{tabular}

Table 1 illustrates the gender breakdown - 97.3\% female and $2.7 \%$ male, but not disaggregate the study participants according to their age and education $(p=0,059)$. However, we can see statistical significance in the work area/place and the years of service there. $(p=0,035)$ The nurse stress level is unified in Table 2 .

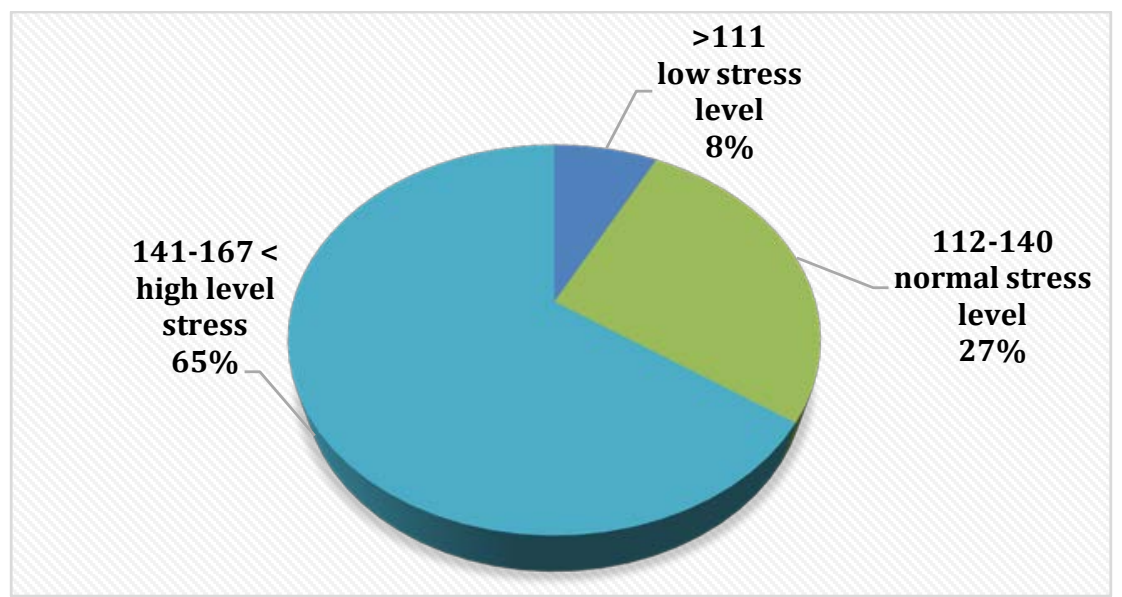

Figure 1. Participants stress levels

We identified the nurses' stress at three levels: high, medium/normal, and low. Figure 1 reveals that the workplace low, normal and high stress level groups were 8,27 and 65 per cent, respectively.

Table 2. Nurse Stress levels (by hospitals)

\begin{tabular}{|c|c|c|c|c|c|}
\hline \multirow[b]{2}{*}{ Hospitals } & \multirow[b]{2}{*}{$\begin{array}{c}\text { Amount } \\
\%\end{array}$} & \multicolumn{3}{|c|}{ Stress level } & \multirow[t]{2}{*}{ Total } \\
\hline & & $\begin{array}{c}\text { Low stress level } \\
(>111)\end{array}$ & $\begin{array}{c}\text { Normal stress level } \\
(112-140)\end{array}$ & $\begin{array}{c}\text { High stress level } \\
(141-167<)\end{array}$ & \\
\hline \multirow{2}{*}{ NCID } & Amount & 8 & 39 & 99 & 146 \\
\hline & $\%$ & $5.5 \%$ & $26.7 \%$ & $67.8 \%$ & $100.0 \%$ \\
\hline \multirow{2}{*}{$\mathrm{NCC}$} & Amount & 5 & 23 & 89 & 117 \\
\hline & $\%$ & $4.3 \%$ & $19.7 \%$ & $76.1 \%$ & $100.0 \%$ \\
\hline \multirow{2}{*}{$\mathrm{NCMH}$} & Amount & 7 & 26 & 56 & 89 \\
\hline & $\%$ & $7.9 \%$ & $29.2 \%$ & $62.9 \%$ & $100.0 \%$ \\
\hline \multirow{2}{*}{ NCTO } & Amount & 16 & 40 & 65 & 121 \\
\hline & $\%$ & $13.2 \%$ & $33.1 \%$ & $53.7 \%$ & $100.0 \%$ \\
\hline \multirow{2}{*}{ Total } & Too & 36 & 128 & 309 & 473 \\
\hline & $\%$ & $7.6 \%$ & $27.1 \%$ & $65.3 \%$ & $100.0 \%$ \\
\hline
\end{tabular}

*NCID - National Center of Infectious Diseases

*NCC - National Center of Cancer

*NCMH - National Center of Mental Health

*NCTO - National Center of Traumatology and Orthopedics 
Table 3 demonstrates the nurse stress levels by their workplaces or hospitals.

The stress level groups were classified by the hospitals: nurses from the National Center of Traumatology and Orthopedics occupied the highest percentage in the low stress group as well as in the normal stress group - their stress level was at 13.2 and 33.1 per cent respectively. Cancer nurses were categorized under the group of high stress level at 76.1 per cent.

What's more cancer nurses occupied the lowest percentage in the low and normal (19.7 per cent) stress groups. NCTO nurses covered the least percentage in high stress levels - 53.7 per cent.

The findings reveal that traumatology nurses' perceived stress level is lower than that of the nurses working at other hospitals. Conversely, we found in our study that cancer nurses predominantly suffer the most from workplace stress.

Nurse stress variability statistics also confirmed these results. For instance, occupational stress statistics of the nurses by hospitals revealed that the NCTO nurses have a lower stress level than the nurses from other hospitals with 144,471 and the National Cancer Center has the highest stress level of 154,641 as compared to other hospitals. However, standard deviations demonstrate that the stress levels had been unstable: the most fluctuated group was the NCTO nurses and the least one were nurses from the National Cancer Center.

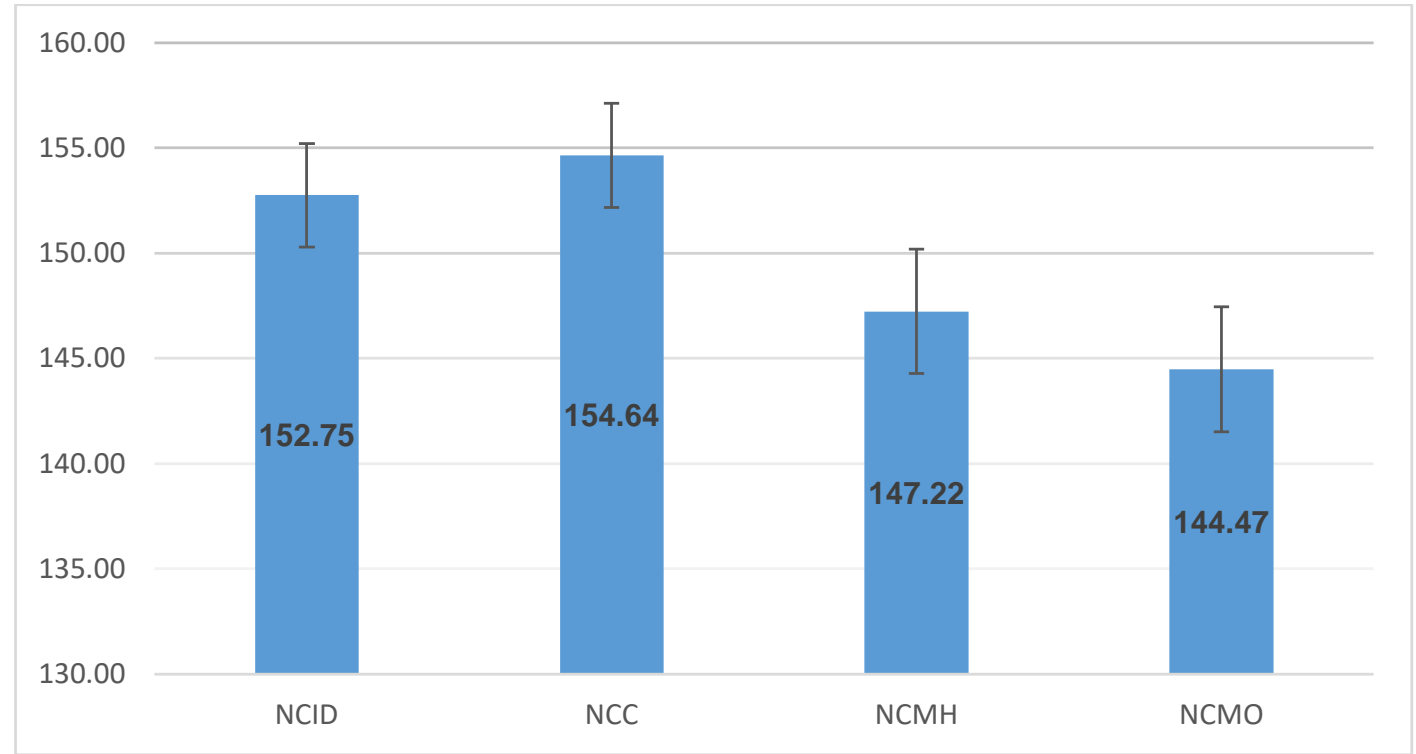

Figure 2. Stress statistical indices among the participants (by hospitals)

We examined whether the nurse stress levels differ using the work-related stress level groups by one-way ANOVA and accordingly, statistical real differences $(\mathrm{F}=3.071),(\mathrm{p}=0,028)$ were confirmed.

Table 3. Stress statistical indices among the participants (ANOVA)

\begin{tabular}{cccccc}
\hline & Sum of Squares & df & Mean Square & F & Sig. \\
\hline Between Groups & 8004.142 & 3 & 2668.047 & 3.071 & .028 \\
Within Groups & 407424.201 & 469 & 868.708 & & \\
\hline
\end{tabular}

In order to evaluate the Workplace stress we added all the corresponding scores to each questions and organized them into the following three levels:

$>91-111$ low-stress level - 1

112-140 normal stress level - 2
141-167< high-stress level - 3

We employed the Japanese-made SALIVA AMYLASE MONITOR apparatus for determining the process of stress level by the participants' salivary alpha amylase (sAA) 
Here we categorized workplace stress in four levels:

0-30(KU/L) low-stress level - 1

31-45(KU/L) normal - 2

46-60(KU/L) high-stress level - 5

Above 61(KU/L) very high-stress level - 6
Using Crosstabs analyzing method, we attempted to figure out the WPS questionnaire with the participants' sAA stress scores. Meanwhile, we compiled the stress levels into three groups by the following scoring method.

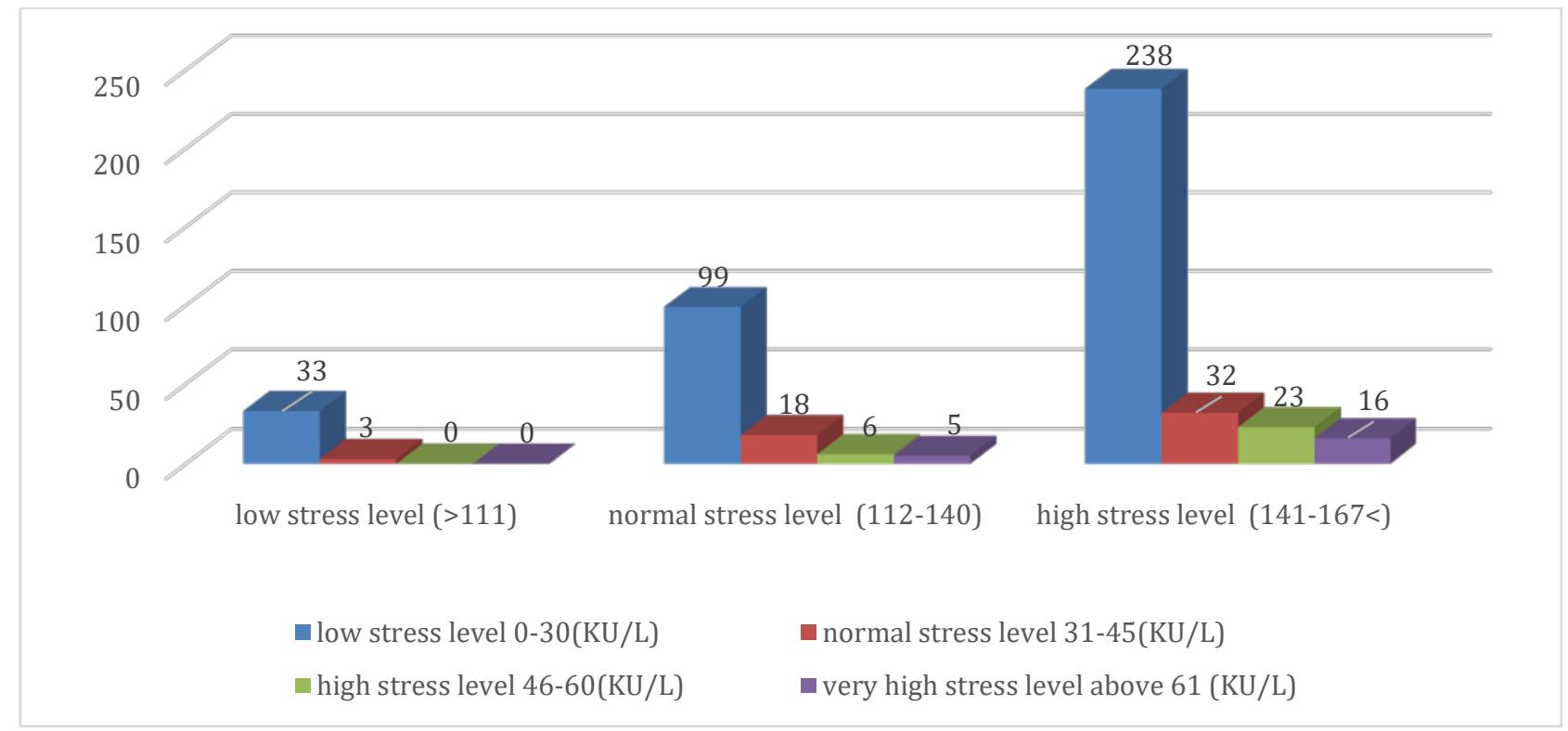

Figure 3. Stress Levels due to WPS and SAA

In accordance with the salivary alpha amylase statistics, in the morning sAA levels were 2-34 (at least 16,083 KU/L) and 2-105 (the highest 25,226 KU/L) in the low and normal stress groups, correspondingly.

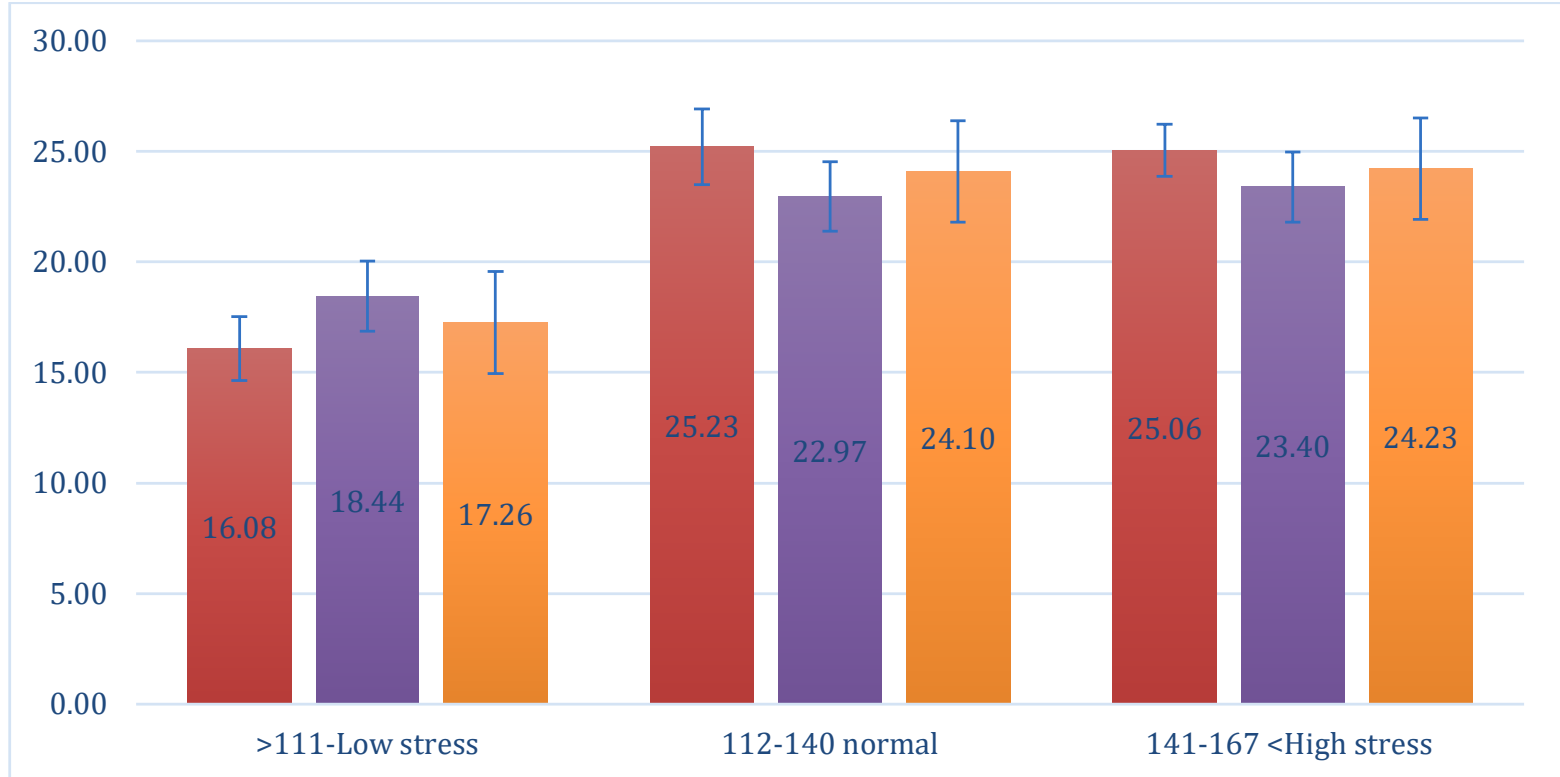

Figure 4. Participants $s A A$ results by their stress levels

The one-way ANOVA results revealed that the differences between the morning sAA level groups were statistically significant
$(\mathrm{F}=3.481, \mathrm{p}=0,032)$. Conversely, the evening sAA levels $(\mathrm{F}=1.256, \mathrm{p}=0,286)$ had no statistical difference $(\mathrm{F}=1.144),(\mathrm{p}=0,331)$. 
Table 4. sAA between the Groups / ANOVA

\begin{tabular}{|c|c|c|c|c|c|c|}
\hline & & Sum of Squares & df & Mean Square & $\mathrm{F}$ & Sig. \\
\hline \multirow{3}{*}{ Morning sAA } & Between Groups & 2711.146 & 2 & 1355.573 & 3.481 & .032 \\
\hline & Within Groups & 183020.131 & 470 & 389.405 & & \\
\hline & Total & 185731.277 & 472 & & & \\
\hline \multirow{3}{*}{ Evening sAA } & Between Groups & 793.893 & 2 & 396.947 & 1.256 & .286 \\
\hline & Within Groups & 148569.198 & 470 & 316.105 & & \\
\hline & Total & 149363.091 & 472 & & & \\
\hline \multirow{3}{*}{ Average sAA } & Between Groups & 1598.160 & 2 & 799.080 & 2.977 & .052 \\
\hline & Within Groups & 126173.478 & 470 & 268.454 & & \\
\hline & Total & 127771.637 & 472 & & & \\
\hline
\end{tabular}

Different scientists, for instance, Weiman (1978), Holmgren [4] (1990) and Rice (1999) have developed diverse self-administered questionnaires in order to identify the workplace stress in its early stage; through early detection of stress, the person or the organization can be prevented or avoid from the numerous unpleasant consequences such as sick-leave, physiological and psychological illnesses, work burnout, and other organizational expenses. Nevertheless, we chose the Rice (1999) WPS self-esteemed questionnaire because we considered that our study participants will be categorized as relatively healthy, that is, they never complain about being sick and quit the job. Furthermore, we decided that it would be reasonable if the participants assess themselves whether they are in work-related stress by reading and getting an idea what can be called workplace stress indeed [5].

It is clear that women dominate nursing around the world, however, regardless of the work environment, requirements, or workload, regardless of gender, all are exposed to workplace stress. The results of our study conform that a lot depend only on individuals. Our study gave proof that due to ANOVA the gender differences on workplace stress is absent $(\mathrm{F}=0.404),(\mathrm{p}=0,525)$ statistically.

According to literature, workplace stress is often treated by the gender of nurses, however, the results vary. Some researchers have noted that there is no gender difference in work stress [6], and others have claimed that female nurses are more vulnerable to various occupational stresses than men [7]. Moreover, some researchers figured out that female nurses are more susceptible to psychological stress, while the male nurses to physiological stressors [8].

If we correlate the age with workplace stress - it would cover personal issues, such as perception, experiences, adapting abilities and so on and so forth.

According to our study, when working stress is related to the age of nurses, the lowest percentage was in the low-stress group, 4.0 per cent in the 31-40 age group, the lowest in the middle group, and 16.2 per cent in the $31-40$ age group, and the highest in the high-stress group a small percentage was identified as 55.9 per cent in the 18-24 age group. This suggests that the stress levels of nurses in the 18-24 age group are lower than in other age groups, while the stress levels of nurses in the 31-40 age group are higher than in other age groups.

The results of this study are similar to the results of a 2013 study by Finnish researchers as well as Mauno, who found that young nurses are less exposed to workplace stress as compared to older nurses [9].

We agree with the global studies that the nurses at younger age are less exposed to work stress because they are working in a fellowship system and they are always relying on coworkers' help.

Certain researchers, such as Takase, Teraoka, and Yabase, suggested in a 2016 study that nurses over the age of twenty-five, who 
want to keep their workplaces, are more stressed than middle-aged and older nurses [10]. The statistically significant differences in the stress levels $(F=1.923)$ and $(p=0.105)$ regarding the nurses' education levels were refuted when we examined it by ANOVA. And the result conforms with Kim Oliver's findings (2007) [11].

\section{CONCLUSIONS}

The results revealed that work-related stress is particularly high among nurses regarding their work places. The one-way ANOVA results revealed that the differences between the morning sAA level groups were statistically significant $(\mathrm{F}=3.481, \mathrm{p}=0,032)$. Conversely, the evening sAA levels $(\mathrm{F}=1.256$,

\section{REFERENCES}

1. McCraty R, Atkinson M, Tomasino D., 2003. Impact of workplace stress reduction program on blood pressure and emotional health in hypertensive employees. J Altern Complem Med, pp. 9:355-369.

2. Maslach C, Schaufeli WB, Leiter MP., 2001. Job burnout. Annual Rev Psychol. [PubMed: 11148311], pp. 52:397-422.

3. Benson H, Beary JF, Carol MP., 1974. The relaxation response. Psychiatry. [PubMed: 4810622], pp. 37:37-46.

4. Anna Frantz., Kristina Holmgren., 2019. The Work Stress Questionnaire (WSQ) reliability and face validity among male workers. Journal of BMC Public Health 1580 (2019).

5. Dan J Braaten., Charles Barnard., 2000. Occupational stress in Mental Health Counselors. A Research Paper Submitted in Partial Fulfillment of the Requirements for the Master of Science Degree With a Major in Marriage \& Family Therapy, pp. 5-11.

6. Wong S., DeSantics G., Staudemayer N., 2007. The relationship between task interdependency and role stress: A revisit of the job demands-control model. J. Manage. Stud, pp. 44:284-303. doi:10.1111/j.1467-6486.2007.00689. [CrossRef] [Google Scholar] [Ref list] .
This study has following limitations: 1 . We did not consider the other ways except the Rice questionnaire, thus there is a need to review perhaps the more accurate methods and compare them. 2. The coverage area was limited. The study was conducted only at 4 hospitals. 3. The rapid test provided limited result.

$\mathrm{p}=0,286)$ had no statistical differences $(\mathrm{F}=1.144),(\mathrm{p}=0,331)$.

Proceeding from our findings, we can clearly see that the nurses at the National Center for Infectious Diseases are working hard under the urged stressed condition.

7. Gunkel M., Lusk E., Wolf B., Li F., 2007. Gender specific effects at work: An empirical study of four countries. Gend. Work Organ. [CrossRef] [Google Scholar] [Ref list], pp. 14:56-79.

8. Burke R., 2002. Work stress and women's health: Occupational status effect. J. Bus. Ethics. [CrossRef] [Google Scholar] [Ref list]), 37, pp. 91-102. doi: 10.1023/A:1014734302972.

9. Mauno, S., Ruokolainen, M., \& Kinnunen, U., 2013. Does aging make employees more resilient to job stress? Age as a moderator in the job stressor-well-being 127 relationship in three Finnish occupational samples. Aging \& Mental Health,17(4), pp.411-412. doi:10.1080/13607863.2012.747077.

10. Takase, M., Teraoka, S., \& Yabase, K., 2016. Retaining the nursing workforce: factor contributing to the reduction of nurses' turnover intention in Japan. Journal of Nursing Management, 24(1), pp. 21-29. doi:10.1111/jonm.12266.

11. Kim Oliver., 2007. An assessment of nurses' experiences of work-related stress through self-reporting and hair cortisol analysis, in a metropolitan hospital in Western Australia. pp 9-11. 
